Short Communication

\title{
Nitrogen-doped Carbon with Hierarchical Porous Structure for Electrocatalysis of Oxygen Reduction Reaction
}

\author{
Xianguo Ma ${ }^{l}$, Shizhong Feng $^{2}$, Shan $\mathrm{Ji}^{1, *}$ \\ ${ }^{1}$ School of Chemical Engineering, Guizhou Institute of Technology, Guiyang, 550003, China, \\ ${ }^{2}$ Gansu petrochina Kunlun Gas Co., Ltd, Lanzhou, 730078, China \\ *E-mail: jissshan@126.com
}

doi: $10.20964 / 2017.08 .70$

Received: 12 April 2017 / Accepted: 12 June 2017 / Published: 12 July 2017

\begin{abstract}
With fuel cells gaining recognition as promising devices for directly converting the chemical energy to electricity, to develop low-cost catalysts for electrocatalysis of oxygen reduction reaction (ORR) has become an active topic in this field. Hierarchical porous carbon materials (HPC) doped with heteroatoms, for instance N, S and Fe, are promising materials for using as catalysts for the ORR due to their low cost, high stability and high efficiency. In this work, we report a low-cost, facile and scalable method to produce nitrogen-doped hierarchical porous carbon material (N-HPC) by pyrolysis of corncobs. The activated N-HPC catalysts exhibit high activity for ORR compared to that of the state-of-the-art commercial Pt/C catalysts.
\end{abstract}

Keywords: N-doped carbon, Oxygen Reduction Reaction, Electrocatalysis, Biomass.

\section{FULL TEXT}

(C) 2017 The Authors. Published by ESG (www.electrochemsci.org). This article is an open access article distributed under the terms and conditions of the Creative Commons Attribution license (http://creativecommons.org/licenses/by/4.0/). 